\title{
What happens after HIV self-testing? Results from a longitudinal cohort of Chinese men who have sex with men
}

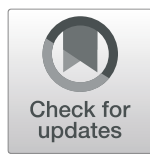

Weiming Tang ${ }^{1,2}$, Wenting Huang ${ }^{1,2,3}$, Haidong $\mathrm{Lu}^{3,4}$, Bolin CaO ${ }^{2,3,5}$, Dan Wu $\mathrm{W}^{1,2,3}$, Jason Ong ${ }^{2,3}$, Hongyun Fu, Ye Zhang ${ }^{1,2}$, Bin Yang ${ }^{1,7}$, Cheng Wang ${ }^{1,7}$, Wei Ma ${ }^{8}$, Chongyi Wei ${ }^{9}$ and Joseph D. Tucker ${ }^{2,3,4,10^{*}}$ (D)

\begin{abstract}
Background: HIV self-testing (HIVST) is a promising approach to expand HIV testing. HIVST is a process in which a person performs an HIV test and interprets the result. Negative HIVST results may encourage men who have sex with men (MSM) to use HIV prevention services. The objective of this study was to examine behaviors (e.g., facilitybased HIV testing, condom use) after a negative HIVST test result among Chinese MSM.

Methods: We collected data from MSM in eight Chinese cities over a 12-month period. This is a secondary analysis of longitudinal cohort data collected as part of an intervention trial to increase HIV testing. Men completed a survey that described sociodemographic information, sexual behaviors, HIV self-testing, and facility-based HIV testing. Men who completed at least one follow-up survey were included in this analysis. Generalized linear mixed models were used to evaluate whether HIVST increased subsequent facility-based HIV testing and consistent condom use.

Results: We included 1219 men. Most men (78.7\%) were under 30 years old and had never been married (87.0\%). 755 (61.9\%) men tested for HIV and 593 (49.3\%) men self-tested during the study period. At baseline, among men who had never been tested for HIV, 44.9\% (314/699) initiated HIVST during the study period. HIVST was associated with subsequent facility-based testing (aOR of 1.87, 95\% Cl: 1.47-2.37). HIVST was also associated with subsequent consistent condom use (aOR $=1.53,95 \% \mathrm{Cl}: 1.13-2.06)$.

Conclusion: HIVST was associated with subsequent facility-based HIV testing and consistent condom use. HIVST may enhance uptake of related HIV prevention services at facilities, suggesting the need for more implementation research.
\end{abstract}

Keywords: Condom use, Facility-based testing, HIV self-testing (HIVST), Longitudinal study, Men who have sex with men

\section{Background}

HIV testing is the first step in the HIV care continuum and an important component of comprehensive HIV services [1]. However, approximately one-quarter of people living with HIV (PLWH) do not know their serological status [2]. This lack of awareness contributes to ongoing HIV transmission in many key populations [3, 4]. In China, men who have sex with men (MSM) have a high

\footnotetext{
* Correspondence: Jdtucker@med.unc.edu

${ }^{2}$ University of North Carolina at Chapel Hill Project-China, Guangzhou 510095, China

${ }^{3}$ SESH Study Group, Guangzhou, China

Full list of author information is available at the end of the article
}

burden of HIV infection [5, 6]. For example, HIV prevalence reached 8\% among MSM in 2015 [6] and a high HIV incidence has been observed [7]. However, a systematic review of 54 studies examining MSM HIV testing in China showed only $47 \%$ of MSM had ever tested for HIV [8]. Low rates of HIV testing among MSM in China are likely related to limited testing options, incomplete protection of privacy, and HIV test-related stigma [9-11].

HIV self-testing (HIVST) is a promising approach for expanding HIV testing. HIVST refers to a process in which a person collects his or her own specimen (oral fluid or blood), performs an HIV test, and interprets the result $[12,13]$. HIVST can be undertaken alone or with a

(c) The Author(s). 2019 Open Access This article is distributed under the terms of the Creative Commons Attribution 4.0 International License (http://creativecommons.org/licenses/by/4.0/), which permits unrestricted use, distribution, and reproduction in any medium, provided you give appropriate credit to the original author(s) and the source, provide a link to the Creative Commons license, and indicate if changes were made. The Creative Commons Public Domain Dedication waiver (http://creativecommons.org/publicdomain/zero/1.0/) applies to the data made available in this article, unless otherwise stated. 
friend, partner, family member, or other person [14, 15]. HIVST enables individuals to test themselves at their convenience. The World Health Organization recommends HIVST as an additional approach for HIV testing [14]. Studies have suggested that HIVST is acceptable and feasible across a wide range of populations and places [16-18]. HIVST provides an additional opportunity for identifying people living with HIV who have not yet been diagnosed [14]. For example, half of the newly identified MSM HIV cases in 2017-2018 in Zhuhai, a Chinese city, were identified through HIVST [19]. HIVST likely increases HIV testing rates, including first-time HIV testing [20]. One study conducted by our study team found that $60 \%$ of MSM HIV self-testers reported that HIV selftesting was their first ever HIV test [21].

However, many MSM who receive HIV testing do not change sexual behaviors or access other HIV prevention services. Few studies have examined what happens to facility-based HIV test uptake or consistent condom use after HIVST. This issue is particularly important among people who receive a negative HIVST and may use their negative HIVST result to justify persistent high-risk behaviors. Better understanding what happens after a negative HIVST result can help us to improve HIV prevention services and linkage to clinical services. The objective of this study was to examine behaviors (e.g., facility-based HIV testing, consistent condom use) after a negative HIVST test result among a longitudinal cohort of Chinese MSM.

\section{Methods}

This is a secondary analysis of cohort data collected as part of a stepped-wedge randomized controlled trial that evaluated the effectiveness of a crowdsourced intervention to promote HIV testing among Chinese MSM [22, 23]. Crowdsourcing has a group attempt to solve a problem or a component of a problem, then share solutions [24]. HIVST promotion materials were developed through a series of crowdsourcing contests. The trial collected data from MSM over a 12-month period starting on July 2016 in eight Chinese cities (Guangzhou, Jiangmen, Shenzhen and Zhuhai in Guangdong Province, Jinan, Jining, Qingdao and Yantai in Shandong Province) (Clinical Trials ID: NCT02796963). These cities were chosen based on the following criteria: 1) previous CDC MSM sentinel surveillance site; 2) capacity for campaign implementation; 3) capacity for intervention implementation at the community level.

\section{Participant recruitment and follow-up}

Detailed information about recruitment and follow-up has been described elsewhere [23]. In brief, a banner link for recruitment was sent to registered Blued, a large gay social network app, users living in selected cities [25].
MSM who were interested in the survey clicked the survey link and were directed to the baseline survey that was hosted by Sojump (Shanghai, China). To be eligible, the men needed to be 16 years old or older, live in one of the eight cities with no plan to move to another city in the next 12 months, be HIV negative or not aware of their HIV status, not have HIV testing in the last 3 months, had anal sex with a man at least once during their lifetime, and be willing to provide their cell phone number for follow-up. Men were assigned into four groups based on the city from which they were recruited. Men were exposed to the HIV testing intervention depending on their group assignment. Cities were randomized into respective intervention groups independently. Eligible men signed an online informed consent and completed the baseline survey instrument. The crowdsourced intervention included an online HIV testing campaign, an online HIVST testing service with free home delivery, and local participatory activities. Data collection occurred at baseline and then quarterly, for a total of five times over a 12-month period. Men diagnosed with HIV infection were censored. Men received 50 RMB ( USD 8.50) for enrolling in the study and participating in each follow-up. The incentives were distributed to men through WeChat, an encrypted instant messaging service. Since the four groups received the same intervention during follow-up, we combined men from the four groups for this analysis. The analysis was restricted to men with at least one follow-up observation.

\section{Measures}

The baseline survey collected socio-demographic information, sexual behaviors, HIV/STI testing history, selfreported HIV status, and whether or not HIV test results were disclosed to their most recent partner. The sociodemographic information included age (in years), city of residence, residency status (resident in the local city, resident of other cities in the same province, or resident of other province), marital status (never married, currently married, divorced or widowed), educational level (high school or less, some college, completed college or more than college), and annual income (\$2500 USD or below, \$2501-8500 USD, \$8501-14,000 USD, or more than $\$ 14,000$ USD). We also collected information regarding self-identified sexual orientation (gay, bisexual, or unsure), ever disclosed sexual orientation to anyone except male partners (dichotomous), and ever disclosed sexual orientation to healthcare providers (dichotomous).

We asked about several sexual behaviors and HIV testing behaviors. We asked men if they had sex with any male partner in the last 3 months (dichotomous) and whether they consistently used a condom with a male partner in the last 3 months (dichotomous). At each follow-up period, we asked about consistent condom use 
with male partners in the past 3 months. In addition, men were asked if they had ever tested for HIV (dichotomous). Among those who had received HIV testing, we asked about ever tested at facility-based sites (dichotomous) and ever self-testing (dichotomous). At each followup period, we asked about HIV facility-based testing in the last 3 months and HIVST in the last 3 months.

We adapted validated scales to measure anticipated HIV stigma [26], HIV testing social norms (attitudes toward HIV testing using six items with a 4-point Likert scale) [27], HIV testing self-efficacy [28], and community engagement in sexual health during the follow-up period [29]. Detailed information on these measures has been reported elsewhere [22, 23, 30].

\section{Statistical analysis}

We used descriptive analysis to examine the distribution of socio-demographic characteristics and sexual behaviors of men who completed at least one follow-up survey. Generalized linear mixed models were used to evaluate the association of HIVST (as a dependent variable) with HIV testing within 3 months following HIVST, facility-based testing within 3 months following HIVST, and condom use with male partners within 3 months following HIVST, after adjusting for secular trend (random effect), age, marital status, and income. Our study is a secondary analysis of a stepped wedge randomized controlled trial. Our findings were similar between the two provinces and we did not adjust for province in our data analysis. All data analyses were completed using SAS 9.4 (SAS, Cary, NC, USA).

\section{Ethics statement}

Ethical approval was obtained from ethics review committees at the Dermatology Hospital of Southern Medical University (Guangzhou, China), the University of North Carolina at Chapel Hill (Chapel Hill, North Carolina), the University of California, San Francisco (San Francisco, California), and Rutgers University (Piscataway, New Jersey) prior to the survey launch. Inform consent was obtained from all the men by e-signing the online informed consent.

\section{Results}

Overall, 1381 MSM who has not tested for HIV in the last 3 months were recruited. Among this group of men, 1219 finished at least one follow-up survey and were included in the data analysis (Table 1).

\section{Social-demographic characteristics and behaviors}

At baseline, about half of the men were recruited from Guangdong Province (49.5\%) while the other half were recruited from Shandong Province (50.5\%). The majority of the 1219 men were under 30 years old (78.7\%), residents
Table 1 Baseline demographic characteristics of men who completed at least one follow-up survey in China, 2016-2017 $(N=1219)$

\begin{tabular}{|c|c|c|c|}
\hline Variables & $n$ & $\%$ & \\
\hline \multirow[t]{4}{*}{ Age Group (years) } & $<20$ & 197 & 16.2 \\
\hline & $20-29$ & 762 & 62.5 \\
\hline & $30-39$ & 207 & 17.0 \\
\hline & 40 or above & 53 & 4.4 \\
\hline \multirow[t]{3}{*}{ Residence status } & The sampling city & 376 & 30.8 \\
\hline & $\begin{array}{l}\text { Other cities in the } \\
\text { province }\end{array}$ & 463 & 38.0 \\
\hline & Other provinces & 380 & 31.2 \\
\hline \multirow[t]{3}{*}{ Marital Status } & Never married & 1061 & 87.0 \\
\hline & Currently married & 110 & 9.0 \\
\hline & Divorced or widowed & 48 & 3.9 \\
\hline \multirow[t]{3}{*}{ Educational level attained } & High school or below & 429 & 35.2 \\
\hline & Some College & 348 & 28.6 \\
\hline & College or above & 442 & 36.3 \\
\hline \multirow[t]{4}{*}{ Annual income (USD) } & 2500 or below & 263 & 21.6 \\
\hline & $2501-8500$ & 654 & 53.7 \\
\hline & $8501-14,000$ & 192 & 15.8 \\
\hline & $>14,000$ & 110 & 9.0 \\
\hline \multirow[t]{2}{*}{ Province } & Guangdong & 603 & 49.5 \\
\hline & Shandong & 616 & 50.5 \\
\hline \multirow[t]{3}{*}{ Sexual Orientation } & Gay & 862 & 70.7 \\
\hline & Bisexual & 304 & 24.9 \\
\hline & Unsure & 53 & 4.4 \\
\hline \multirow[t]{2}{*}{ Ever disclosed sexual orientation } & Yes & 794 & 65.1 \\
\hline & No & 425 & 34.9 \\
\hline \multirow{2}{*}{$\begin{array}{l}\text { Ever disclosed sexual orientation } \\
\text { to health providers }\end{array}$} & Yes & 251 & 31.6 \\
\hline & No & 543 & 68.4 \\
\hline \multirow{2}{*}{$\begin{array}{l}\text { Had a male partner in the } \\
\text { last } 3 \text { months }\end{array}$} & Yes & 657 & 53.9 \\
\hline & No & 562 & 46.1 \\
\hline \multirow{2}{*}{$\begin{array}{l}\text { Consistently used a condom with } \\
\text { male partners in the last } 3 \text { months }\end{array}$} & Yes & 333 & 50.7 \\
\hline & No & 324 & 49.3 \\
\hline \multirow[t]{2}{*}{ Ever tested for HIV } & Yes & 520 & 42.7 \\
\hline & No & 699 & 57.3 \\
\hline \multirow[t]{2}{*}{ Ever self-tested for HIV } & Yes & 202 & 16.6 \\
\hline & No & 1017 & 83.4 \\
\hline \multirow{2}{*}{$\begin{array}{l}\text { HIVST as first HIV testing before } \\
\text { the study }{ }^{c}\end{array}$} & Yes & 114 & 21.9 \\
\hline & No & 406 & 78.1 \\
\hline
\end{tabular}

Note:

${ }^{a}$ Among people reported ever disclosed sexual orientation to anyone else except male partner

${ }^{\mathrm{b}}$ Among people who had a male partner in the last 3 months

camong people who tested for HIV before (520) 
of the province (68.8\%), never married (87.0\%), and attended some college (64.8\%). In addition, only $9.0 \%$ of the men had an annual income greater than USD 14,000.

Most (70.7\%) men self-identified as gay, and $65.1 \%$ reported that they disclosed their sexual orientation to anyone other than their male sexual partners. Among men who disclosed their sexual orientation $(n=794), 31.6 \%$ disclosed their sexual orientation to health care providers.

Approximately half of men (53.9\%) reported that they had sex with male partners in the last 3 months. Approximately half of men $(50.7 \%)$ consistently used a condom when having sex with male partners. At baseline, $53.9 \%(657 / 1219)$ of men reported that they engaged in anal sex with male partners in the last 3 months. This proportion was $58.1 \%(651 / 1120)$, 56.7\% (617/1088), $58.7 \%(613 / 1044)$ and $60.6 \%(625 / 1031)$ during the first, second, third and fourth follow-up period, respectively (Additional file 1).

\section{HIV testing}

Seven hundred and fifty-five (61.9\%) men tested for HIV and 593 (49.3\%) men self-tested during the study period. Of the 1219 people who completed at least one followup survey, about 13.0\% (158/1219), 36.8\% (449/1219), $49.7 \%(606 / 1219)$ and $61.9 \%(755 / 1219)$ of men tested once (including facility-based testing and self-testing) during the first 3 months, first 6 months, first 9 months and in 12 months of follow-up, respectively.

In addition, about 10.3\% (126/1219), 26.4\% (322/1219), $38.1 \%$ (464/1219), and $48.7 \%(593 / 1219)$ of men had self-tested at least once during the first 3 months, first 6 months, first 9 months and in 12 months of follow-up, respectively (Fig. 1). Among the 699 men who never tested for HIV before, 314 (44.9\%) used HIVST during the study period. Among men who used HIVST, 89 (15.0\%) men reported that their HIV testing results were positive. Of these 89 men, 43 (48.3\%) reported that they confirmed their testing results at facility-based sites within the same three-month follow-up period. All of them were confirmed to be living with HIV infection.

\section{Facility-based testing and condom use following HIVST}

The generalized linear mixed model showed that a negative HIVST result was associated with subsequent overall HIV testing and subsequent facility-based testing, with adjusted ORs (aORs) of 2.45 (95\% CI: 1.99, 3.01) and 1.46 (95\% CI: 1.15, 1.86), respectively. We also found that HIVST was associated with subsequent consistent condom use with male partners, with an OR of 1.53 (95\% CI: 1.13, 2.06) (Table 2).

\section{Discussion}

HIVST can reach hard-to-find key populations who have never used facility-based HIV testing [14, 31]. Previous studies focused on evaluating the feasibility and acceptability of HIVST [32], assessing the testing accuracy of HIVST kits [33], and piloting HIVST distribution models [34]. This study adds to the literature by evaluating facility-based testing and condom use following a negative HIVST result. Our findings suggest that HIVST is associated with subsequent facility-based HIV testing and consistent condom use. Our data have implications for expanding HIV prevention services among MSM in China.

We found that men with a negative HIVST result were more likely to receive subsequent facility-based HIV

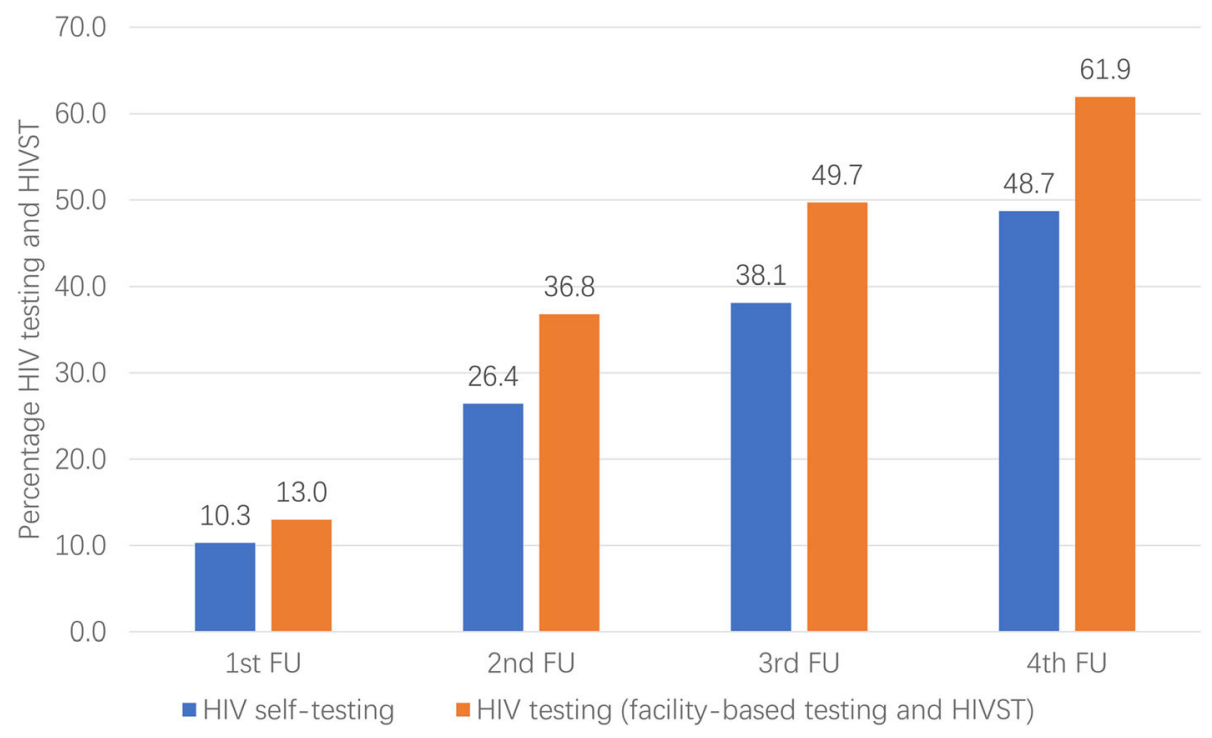

Fig. 1 Cumulative HIV testing (including HIV self-testing) uptake among Chinese MSM, 2016-2017 ( $N=1219)$ 
Table 2 The association of HIVST on following overall HIV testing, facility-based testing, and condom use among MSM in China, 2016-2017. $(N=1219)$

\begin{tabular}{|c|c|c|c|}
\hline \multirow[t]{2}{*}{ Variables } & & \multicolumn{2}{|l|}{ Measures (95\% Cls) } \\
\hline & & Crude OR $(95 \% \mathrm{Cls})^{\mathrm{a}}$ & Adjusted OR $(95 \% \mathrm{Cls})^{\mathrm{b}}$ \\
\hline \multirow[t]{2}{*}{ Overall subsequent HIV testing } & No & Ref & \\
\hline & Yes & $2.50(2.04,3.06)$ & $2.45(1.99,3.01)$ \\
\hline \multirow[t]{2}{*}{ Subsequent facility-based testing } & No & Ref & \\
\hline & Yes & $1.87(1.47,2.37)$ & $1.46(1.15,1.86)^{c}$ \\
\hline \multirow[t]{2}{*}{ Subsequent HIV self-testing } & No & Ref & \\
\hline & Yes & $1.38(1.04,1.82)$ & $1.42(1.07,1.88)$ \\
\hline \multirow[t]{2}{*}{ Consistent condom use with a male partner } & No & Ref & \\
\hline & Yes & $1.56(1.16,2.10)$ & $1.53(1.13,2.06)$ \\
\hline \multirow[t]{3}{*}{ Community engagement } & Not Increased & Ref & \\
\hline & Increased & $1.13(0.32,3.99)$ & $1.21(0.31,4.66)$ \\
\hline & & $\begin{array}{l}\text { Crude scale difference }(95 \% \mathrm{Cls}) \\
\text { for continuous outcomes }\end{array}$ & Adjusted scale difference $(95 \% \mathrm{Cls})^{b}$ \\
\hline \multicolumn{2}{|l|}{ Anticipated Stigma } & $-0.010(-0.055,0.035)$ & $-0.008(-0.053,0.037)$ \\
\hline \multicolumn{2}{|l|}{ Social norm } & $-0.019(-0.008,0.065)$ & $-0.019(-0.009,0.064)$ \\
\hline \multicolumn{2}{|l|}{ Self-efficacy } & $-0.022(-0.019,0.062)$ & $-0.021(-0.019,0.062)$ \\
\hline
\end{tabular}

testing. This finding contrasts an Australian MSM study which reported that facility-based HIV test uptake did not change following HIV self-testing [35]. This difference may be due to variations in HIVST models [36] or the already high HIV facility-based HIV testing rates among MSM in Australia [35]. Our finding is similar to other research which suggest that HIVST can serve as an entry point for pre-exposure prophylaxis [37] and male circumcision [38]. Other facility-based HIV prevention services such as STI testing could also be integrated with HIVST.

We found that men who received HIVST were subsequently more likely to report consistent condom use. A previous review found mixed evidence regarding whether HIVST is associated with subsequent condom use [39]. However, studies suggest that an additional HIV prevention benefit of HIVST may be the option to test at the point of sex $[32,40]$. Testing at the point of sex refers to individuals using HIVST to screen potential sex partners immediately before sex and then making a decision whether or not to have sex based on the test results [18]. This finding underscores the potential behavioral advantages of HIVST.

This study has policy and research implications. From a policy perspective, HIVST is a potential tool for promoting other HIV prevention services, especially among MSM who do not currently access facility-based services. The potential for HIVST to drive facility-based testing may help to reach MSM, identify HIV cases, link people to care, and provide PrEP services. National-level policies supporting HIVST in the broader context of HIV prevention services may help to formalize this integration. From a research perspective, the public health benefits of HIVST suggest the need for more implementation research [21, 41]. Optimizing the scale-up of smaller, community-based HIVST pilots into larger programs will require pragmatic trials and process evaluations [32, 42].

This study has several limitations. First, men in this study were recruited through a single geosocial networking mobile phone application, Blued. Our sample of MSM were young and well-educated. This group of MSM may be more likely to use HIVST compared to other groups of MSM in China. Making inferences based on our data to other MSM groups should be done with caution. Second, the information collected in this study mainly relied on self-report, leading to social desirability bias and information bias. However, data from the stepped wedge trial indicated that there was a high agreement between self-reported data and data from photo-verification. Third, some people included in the analysis did not attend all of the follow-up surveys. As a result, our study may underestimate HIVST uptake rates. Last, the HIV self-testing rate reported in this study was collected in a trial setting, which may overestimate uptake. However, we did not aim to compare 
this rate with other studies, and this finding suggests strong demand for HIVST among Chinese MSM.

\section{Conclusions}

HIVST is a useful tool for expanding HIV testing. Our data show that HIVST is associated with subsequent facility-based testing and consistent condom use among MSM in China. HIVST could serve as an entry point for other HIV prevention services and contribute to comprehensive HIV services.

\section{Supplementary information}

Supplementary information accompanies this paper at https://doi.org/10. 1186/s12879-019-4455-8.

Additional file 1. Proportion of people who have had sex with male partners in the last 3 months among Chinese MSM, 2016-2017 ( $N=$ 1219)

\section{Abbreviations}

HIV: Human Immunodeficiency virus; HIVST: HIV self-testing; MSM: Men who have sex with men; OR: Odds ratio; PLWH: People living with HIV; RMB: Ren Min Bi; USD: US dollars

\section{Acknowledgments}

The authors thanks Philip Zhang for helping review an earlier version of this manuscript. Thanks to all those who contributed to this study, especially the study men.

\section{Ethical approval and consent to participate}

Ethical approval was obtained from the ethics review committees at the Dermatology Hospital of Southern Medical University (Guangzhou, China), the University of North Carolina at Chapel Hill (Chapel Hill, North Carolina), the University of California, San Francisco (San Francisco, California), and Rutgers University (Piscataway, New Jersey) prior to the survey launch. Inform consent was obtained from all the men by e-signing the inform consent online.

\section{Authors' contributions}

WT drafted this manuscript. BC, JO, HF, YZ, BY, WM, CW1 (Wang Cheng), and JT collected the data. HL, DW, and CW2 (Chongyi Wei) helped with data analysis. All people have read, reviewed, and approved this manuscript. WT and $\mathrm{JT}$ conceived this study.

\section{Funding}

This study received support from the National Key Research and Development Program of China (2017YFE0103800), the National Institutes of Health (NIAID 1R01AI114310-01), UNC-South China STD Research Training Center (FIC 1D43TW009532-01), UNC Center for AIDS Research (NIAID 5P30AI050410), NIMH (R34MH109359), NIAID (K24Al143471), NICHD (UG3HD096929), NIMH (R34MH1 19963), National Science and Technology Major Project (2018ZX10101-001-001-003), and SESH (Social Entrepreneurship to Spur Health) Global. The funders had no role in study design, data collection, and analysis, decision to publish, or preparation of the manuscript

\section{Availability of data and materials}

The datasets used and analyzed during the current study are available from the corresponding author on reasonable request.

\section{Consent for publication}

Not Applicable.

\section{Competing interests}

The authors declare that they have no conflict of interest. Dr. Weiming Tang is an associate editor of BMC Infectious Diseases, and Dr. Joseph D. Tucker is a section editor of BMC Infectious Diseases.

\section{Author details}

'Dermatology Hospital, Southern Medical University Guangzhou, Guangzhou, China. ${ }^{2}$ University of North Carolina at Chapel Hill Project-China, Guangzhou 510095, China. ${ }^{3}$ SESH Study Group, Guangzhou, China. ${ }^{4}$ School of Public Health, University of North Carolina at Chapel Hill, Chapel Hill, USA. ${ }^{5}$ College of Mass Communication, Shenzhen University, Shenzhen, China. ${ }^{6}$ Division of Community Health and Research, Eastern Virginia Medical School, Norfolk, Virginia, USA. ${ }^{7}$ School of Public Health, Southern Medical University, Guangzhou, China. ${ }^{8}$ School of Public Health, Shandong University, Jinan, China. ${ }^{9}$ Rutgers University, Brunswick, NJ, USA. ${ }^{10}$ Faculty of Infectious and Tropical Diseases, London School of Hygiene and Tropical Medicine, London, UK.

Received: 18 March 2019 Accepted: 10 September 2019

Published online: 14 September 2019

\section{References}

1. Kilmarx PH, Mutasa-Apollo T. Patching a leaky pipe: the cascade of HIV care. Curr Opin HIV AIDS. 2013;8(1):59-64.

2. UNAIDS. UNAIDS Data 2018. Geneva; 2018.

3. Hall HI, Holtgrave DR, Maulsby C. HIV transmission rates from persons living with HIV who are aware and unaware of their infection. Aids. 2012;26(7):893-6.

4. Brenner BG, Roger M, Routy J-P, Moisi D, Ntemgwa M, Matte C, et al. High rates of forward transmission events after acute/early HIV-1 infection. J Infect Dis. 2007;195(7):951-9.

5. Qin Q, Guo W, Tang W, Mahapatra T, Wang L, Zhang N, et al. Spatial analysis of the human immunodeficiency virus epidemic among men who have sex with men in China, 2006-2015. Clin Infect Dis. 2017;64(7):956-63.

6. $\quad$ Tang S, Tang W, Meyers K, Chan P, Chen Z, Tucker JD. HIV and syphilis among men who have sex with men and transgender individuals in China: a scoping review. Lancet. 2016;388:S74.

7. Zhang W, Xu J-J, Zou H, Zhang J, Wang N, Shang H. HIV incidence and associated risk factors in men who have sex with men in mainland China: an updated systematic review and meta-analysis. Sex Health. 2016;13(4):373-82

8. Zou H, Hu N, Xin Q, Beck J. HIV testing among men who have sex with men in China: a systematic review and meta-analysis. AIDS Behav. 2012; 16(7):1717-28.

9. Kaufman MR, Cornish F, Zimmerman RS, Johnson BT. Health behavior change models for HIV prevention and AIDS care: practical recommendations for a multi-level approach. J Acquir Immune Defic Syndr. 2014;66(Suppl 3):S250.

10. Wei C, Yan H, Yang C, Raymond HF, Li J, Yang H, et al. Accessing HIV testing and treatment among men who have sex with men in China: a qualitative study. AIDS Care. 2014;26(3):372-8.

11. Song Y, Li X, Zhang L, Fang X, Lin X, Liu Y, et al. HIV-testing behavior among young migrant men who have sex with men (MSM) in Beijing, China. AIDS Care. 2011:23(2):179-86.

12. Choko AT, MacPherson P, Webb EL, Willey BA, Feasy H, Sambakunsi R, et al. Uptake, accuracy, safety, and linkage into care over two years of promoting annual self-testing for HIV in Blantyre, Malawi: a community-based prospective study. PLoS Med. 2015;12(9):e1001873.

13. Wong V, Johnson C, Cowan E, Rosenthal M, Peeling R, Miralles M, et al. HIV self-testing in resource-limited settings: regulatory and policy considerations. AIDS Behav. 2014;18(4):415-21.

14. WHO. Guidelines on HIV self-testing and partner notification: supplement to consolidated guidelines on HIV testing services. Geneva: World Health Organization; 2016.

15. Venter F, Majam M, Jankelowitz L, Adams S, Moorhouse M, Carmona S, et al. South African HIV self-testing policy and guidance considerations. South Afr J HIV Med. 2017;18(1):775.

16. Indravudh PP, Choko AT, Corbett EL. Scaling up HIV self-testing in subSaharan Africa: a review of technology, policy and evidence. Curr Opin Infect Dis. 2018:31(1):14

17. Krause J, Subklew-Sehume F, Kenyon C, Colebunders R. Acceptability of HIV self-testing: a systematic literature review. BMC Public Health. 2013;13(1):735.

18. Figueroa C, Johnson C, Verster A, Baggaley R. Attitudes and acceptability on HIV self-testing among key populations: a literature review. AIDS Behav. 2015;19(11):1949-65.

19. Wu D, Smith KM, Ong J, Ritchwood T, Fu H, Pan S, et al. Social-media based secondary distribution of HIV self-testing among Chinese men 
who have sex with men: a pilot implementation program assessment. Mexico city: IAS; 2019

20. Sabapathy K, Van den Bergh R, Fidler S, Hayes R, Ford N. Uptake of homebased voluntary HIV testing in sub-Saharan Africa: a systematic review and meta-analysis. PLoS Med. 2012;9(12):e1001351.

21. Oin Y, Tang W, Nowacki A, Mollan K, Reifeis SA, Hudgens MG, et al. Benefits and potential harms of HIV self-testing among men who have sex with men in China: an implementation perspective. Sex Transm Dis. 2017:44(4):233.

22. Tang W, Wei C, Cao B, Wu D, Li K, Lu H, et al. Crowdsourcing to expand HIV testing among men who have sex with men in China: a closed cohort stepped wedge cluster randomized controlled trial. PLoS Med. 2018;15(8): e1002645. https://doi.org/10.1371/journal.pmed.1002645.

23. SESH, Tucker JD. Crowdsourcing to promote HIV testing among MSM in China: study protocol for a stepped wedge randomized controlled trial. Trials. 2017;18(1):447.

24. Tucker JD, Day S, Tang W, Bayus B. Crowdsourcing in medical research: concepts and applications. Peer. 2019;7:e6762.

25. News P. Former closeted police officer created gay app with 27 million users. 2017. http://www.pinknews.co.uk/2017/01/12/closeted-chinese-policeofficer-behind-a-gay-app-with-27-million-users/. Accessed 12 Sept 2019.

26. Golub SA, Gamarel KE. The impact of anticipated HIV stigma on delays in HIV testing behaviors: findings from a community-based sample of men who have sex with men and transgender women in new York City. AIDS Patient Care STDs. 2013;27(11):621-7.

27. Pettifor A, MacPhail C, Suchindran S, Delany-Moretlwe S. Factors associated with HIV testing among public sector clinic attendees in Johannesburg, South Africa. AIDS Behav. 2010;14(4):913-21.

28. Gu J, Lau J, Tsui H. Psychological factors in association with uptake of voluntary counselling and testing for HIV among men who have sex with men in Hong Kong. Public Health. 2011;125(5):275-82.

29. Zhang TP, Liu C, Han L, Tang W, Mao J, Wong T, et al. Community engagement in sexual health and uptake of HIV testing and syphilis testing among MSM in China: a cross-sectional online survey. J Int AIDS Soc. 2017:1-10.

30. Tang W, Liu C, Cao B, Pan SW, Zhang Y, Ong J, et al. Receiving HIV Serostatus disclosure from partners before sex: results from an online survey of Chinese men who have sex with men. AIDS Behav. 2018:1-10.

31. Qin Y, Tang W, Nowacki A, Mollan K, Reifeis SA, Hudgens MG, et al. Benefits and potential harms of human immunodeficiency virus self-testing among men who have sex with men in China: an implementation perspective. Sex Transm Dis. 2017:44(4):233-8.

32. Zhong F, Tang W, Cheng W, Lin P, Wu Q, Cai Y, et al. Acceptability and feasibility of a social entrepreneurship testing model to promote HIV selftesting and linkage to care among men who have sex with men. HIV Med. 2017;18(5):376-82.

33. Figueroa C, Johnson C, Ford N. Reliability of HIV rapid diagnostic tests for self-testing performed by self-testers compared to health-care workers: a systematic review and meta-analysis. Lancet HIV. 2018;5: e277-e90.

34. Oldenburg CE, Ortblad KF, Chanda MM, Mwanda K, Nicodemus W, Sikaundi R, et al. Zambian peer educators for HIV self-testing (ZEST) study: rationale and design of a cluster randomised trial of HIV selftesting among female sex workers in Zambia. BMJ Open. 2017;7(4): e014780.

35. Jamil MS, Prestage G, Fairley CK, Grulich AE, Smith KS, Chen M, et al. Effect of availability of HIV self-testing on HIV testing frequency in gay and bisexual men at high risk of infection (FORTH): a waiting-list randomised controlled trial. Lancet HIV. 2017;4(6):e241-e50.

36. Han L, Wei C, Muessig KE, Bien CH, Meng G, Emch ME, et al. HIV test uptake among MSM in China: implications for enhanced HIV test promotion campaigns among key populations. Glob Public Health. 2017;12(1):31-44.

37. TheGloalFund. Briefing note: Operational research to improve implementation and uptake of HIV self-testing. Geneva; 2016.

38. Johnson C. HIV self-testing offers new opportunities for health workers and lay providers. Geneva: World Health Organization; 2017. https:// www.hivsharespace.net/blog/hiv-self-testing-offers-new-opportunitieshealth-workers-and-lay-providers

39. Stevens DR, Vrana CJ, Dlin RE, Korte JE. A global review of HIV self-testing: themes and implications. AIDS Behav. 2017:1-16.
40. Carballo-Dieguez A, Frasca T, Balan I, Ibitoye M, Dolezal C. Use of a rapid HIV home test prevents HIV exposure in a high risk sample of men who have sex with men. AIDS Behav. 2012;16(7):1753-60.

41. Han L, Bien $C H$, Wei $C$, Muessig KE, Yang M, Liu F, et al. HIV selftesting among online MSM in China: implications for expanding HIV testing among key populations. J Acquir Immune Defic Syndr. 2014; 67(2):216-21.

42. Tang W, Wu D. Opportunities and challenges for HIV self-testing in China. Lancet HIV. 2018;5(11):e611-e2.

\section{Publisher's Note}

Springer Nature remains neutral with regard to jurisdictional claims in published maps and institutional affiliations.
Ready to submit your research? Choose BMC and benefit from:

- fast, convenient online submission

- thorough peer review by experienced researchers in your field

- rapid publication on acceptance

- support for research data, including large and complex data types

- gold Open Access which fosters wider collaboration and increased citations

- maximum visibility for your research: over $100 \mathrm{M}$ website views per year

At BMC, research is always in progress.

Learn more biomedcentral.com/submissions 